\title{
Opiniões e sugestões dos alunos acerca da disciplina de Técnicas Laboratoriais de Química
}

\author{
LA URINDA LEITE* e SUSANA SÁ*
}

Este artigo tem como objectivo apresentar os resultados de uma investigação sobre: i) o que pensam os alunos de Técnicas Laboratoriais de Química Bloco I acerca da relação da disciplina com a vida do dia-a-dia e acerca da relação entre as aulas teóricas e as aulas laboratoriais e ii) o que os alunos manteriam e alterariam na disciplina.

Os dados foram recolhidos através de um questionário aplicado a 312 alunos, de 14 escolas e 24 professores. Os resultados indicam que i) na opinião dos alunos, existe uma maior relação entre as aulas teóricas e as aulas práticas do que entre as experiências laboratoriais de TLQ e a vida do dia-a-dia e ii) que os alunos gostariam de ter melhores condições logísticas e pedagógico-didácticas.

\section{INTRODUÇÃO}

A disciplina de Técnicas Laboratoriais de Química (TLQ) entrou em funcionamento no ano lectivo de 1993/94, na sequência da recente Reforma Curricular.

De acordo com o respectivo programa (1), a leccionação desta disciplina deve ser orientada numa perspectiva predominantemente prática, não descurando, no entanto, o suporte científico-teórico, que se afirma ser importante para desenvolver no aluno "a estruturação do raciocínio, o espírito crítico-científico e a adaptabilidade a novas situações". Defende-se, ainda, que a disciplina constitua um espaço "onde o aluno passa da teoria à prática ou vice versa", que lhe permita aplicar conceitos e fazer "uma ligação permanente à vida do quotidiano".

Neste contexto, parece pertinente perguntar em que medida estarão estas recomendações a ser explicitamente postas em prática, de modo a facilitar não só a (re) construção consciente e integrada dos diferentes conhecimentos e experiências adquiridos pelos alunos em TLQ, mas tam- bém o relacionamento destes com o dia-a-dia?

Assim, neste artigo apresenta-se um estudo que teve como objectivos:

- investigar o que pensam os alunos de TLQ - Bloco I acerca da relação da disciplina com a vida do diaa-dia e acerca da relação entre as aulas teóricas e as aulas laboratoriais, nessa mesma disciplina;

- identificar as alterações que os alunos gostariam de ver introduzidas na disciplina.

\section{METODOLOGIA}

\section{Descrição do estudo}

$O$ estudo consistiu na recolha de opiniões de alunos de TLQ Bloco I sobre a disciplina, tendo, para o efeito, os alunos sido inquiridos, através de um questionário, acerca dos aspectos referidos nos objectivos anteriormente apresentados.

O questionário foi aplicado por professores de Ciências FísicoQuímicas ou TLQ, no final do ano lectivo de 94/95.

\section{Amostra}

Participaram no estudo 312 alunos de TLQ - Bloco I, oriundos de 14 escolas e 24 professores. As escolas envolvidas no estudo pertenciam aos distritos de Braga, Porto e Aveiro.

Não sabemos se os alunos com que trabalhámos são ou não representativos dos alunos portugueses de TLQ - Bloco I. No entanto, pensamos que o facto de eles serem oriundos de diversas escolas e professores nos dá garantias de que os resultados deste estudo constituem um indicador do sentimento dos alunos Portugueses de TLQ.

\section{Construção e validação do instrumento}

Para este trabalho elaborou-se um questionário constituído por duas partes.

A primeira parte continha itens escalares, adaptados de questionários previamente utilizados por Fraser et al. (2) e por Araújo (3). A cada item os sujeitos deveriam responder seleccionan- do um dos graus da seguinte escala:

$$
\begin{gathered}
\text { 1-Nunca 2-Raramente 3-Algumas vezes } \\
\text { 4-Muitas vezes 5-Sempre }
\end{gathered}
$$

Por análise factorial, verificou-se o agrupamento de nove itens em dois factores, F1 e F2, como se segue:

F 1 - Relação entre as aulas teóricas e as aulas laboratoriais de TLQ

1 - Quando vamos para uma aula laboratorial não temos bases teóricas para compreender as experiências realizadas

2 - Usamos durante as actividades laboratoriais, a matéria aprendida nas aulas teóricas

3 - A matéria dada nas aulas teóricas é muito diferente dos assuntos tratados nas aulas laboratoriais

4 - O trabalho das aulas laboratoriais ajuda-nos a compreender a teoria dada nas aulas teóricas

5 - O trabalho laboratorial e as aulas teóricas de TLQ não estão relacionados

F 2 - Relação entre as experiências laboratoriais de TLQ e o dia-a-dia

6 - As experiências realizadas em TLQ permitiram "ver" a aplicação prática da Química

7 - As experiências realizadas em TLQ não têm utilidade para a vida real

8 - As experiências realizadas em TLQ têm a ver com fenómenos da vida corrente

9 - As aulas laboratoriais de TLQ permitiram compreender fenómenos da vida corrente

Cada factor apresenta uma consistência interna superior ao valor mínimo (0.7) exigido para este tipo de teste (4) e a correlação entre estes dois factores (0.513) não é muito elevada. Assim, os itens incluídos em cada um dos factores têm uma certa interconexão e medem uma mesma dimensão que é diferente da dimensão medida pelos itens incluídos no outro factor. Podemos, portanto, analisar essas duas dimensões separadamente. 
A segunda parte do questionário era constituida pela seguinte questão de resposta livre: “ O que modificarias e o que manterias na disciplina de TLQ, se passasses a ser tu o(a) professor(a)?".

\section{RESULTADOS}

\section{Opiniões dos alunos}

Para tratar os dados recolhidos com a primeira parte do questionário, inverteu-se a escala no caso dos itens negativos (itens 1, 3, 5 e 7), de modo a que um dado grau da escala tenha o mesmo significado para qualquer item: 1 - Nunca/Não Desejável -> 5 - Sempre/Desejável; .

A figura 1 mostra a média $( \pm 1$ desvio padrão) das respostas dadas pelos sujeitos aos diferentes itens.

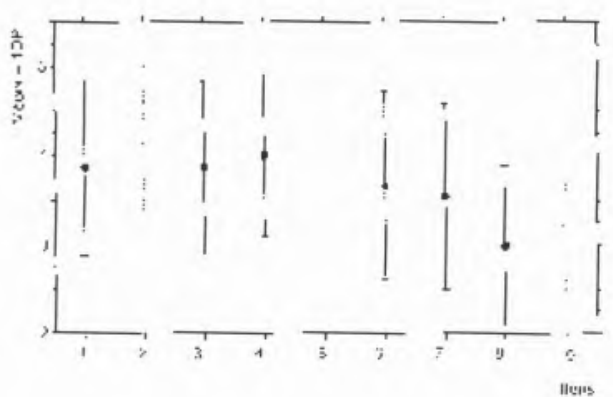

Fig. 1: Média ( \pm IDP) para cada item

As médias obtidas pelos itens 1 a 5 (associados ao Factor 1) são superiores às médias obtidas pelos itens 6 a 9 (associadas ao Factor 2).

A média mais elevada (4.16) foi obtida pelo item 2 , o que significa que os alunos sentem que usam "Muitas vezes" nas aulas práticas a

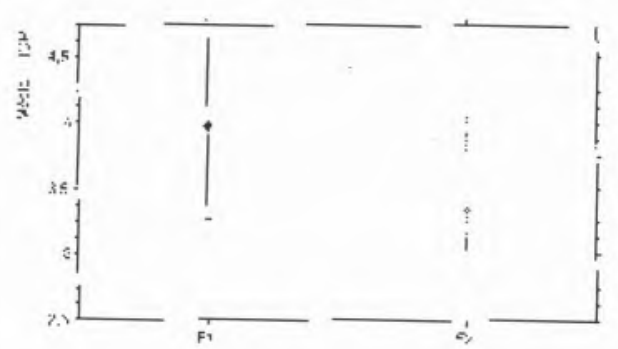

Fig. 2: Média ( 1 1DP) para cada factor matéria aprendida nas aulas teóricas.

A média mais baixa (2.99) verifica-se para o item 8 , o que significa que, para os alunos, as experiências de TLQ tendem a estar apenas "Algumas vezes" relacionadas com o dia-a-dia.

Contudo, os elevados valores de desvio padrão indicam um consenso não muito elevado entre os alunos relativamente ao conteúdo de cada um dos diferentes itens.

O Factor 1 obteve uma média superior à do Factor 2, sendo a dispersão dos resultados semelhante nos dois factores (Fig. 2).

Assim, a opinião dos alunos indica que eles sentem mais frequentemente a relação entre as aulas teóricas e as aulas experimentais do que a relação entre o que fazem em TLQ e o dia-a-dia.

De acordo com o gráfico 1, cerca de $75 \%$ dos sujeitos atribuíram pontuação "elevada" ( $\geq 3.5$ ) ao Factor 1.

A correspondente percentagem, para o Factor 2 é inferior a 50\% (gráfico 2) e está próxima da percentagem que lhe atribuíu pontuação moderada (entre 2.5 e 3.5, inclusivé).

Há, portanto, muito mais alunos a afirmarem que as aulas teóricas têm uma relação "elevada" com as aulas experimentais do que a reconhecerem a existência de uma relação deste tipo entre as actividades experimentais realizadas em TLQ e o dia-a-dia.

\section{Sugestões dos alunos}

A análise das respostas dos alunos à questão aberta mostra que eles se centram essencialmente nos aspectos que gostariam de ver alterados. Na verdade, apenas 21 alunos mencionam aspectos a manter, sendo unânimes em referir o bom relacionamento que têm com o(a) professor(a). Em nossa opinião, este resultado não pode ser interpretado como significando, necessariamente, que os alunos consideram que tudo o resto precisa de ser alterado, mas antes como constituindo um indicador da elevada importância que reconhecem a uma boa relação afectiva com o(a) professor(a).

No que respeita às alterações, verifica-se, pela análise do quadro 1 ,

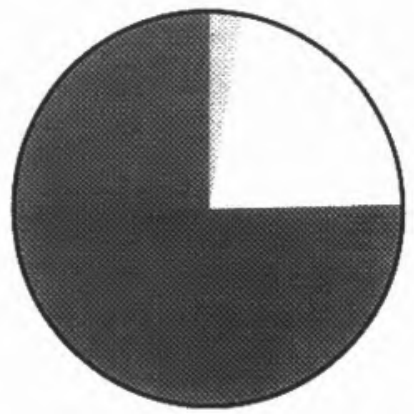

$\square$ Baixa C. Moderada

- Elevada

Gráfico 1: Classificação das pontuações médias atribuídas pelos alunos ao Factor 1 .

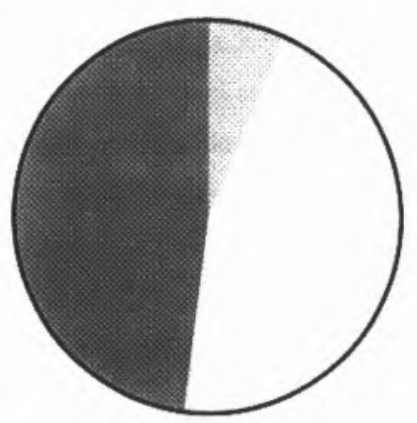

Gráfico 2: Classificação das pontuações médias atribuídas pelos alunos ao Factor 2

que as de ordem logística são aquelas que gozam de maior consenso entre os alunos.

De notar que mais de $30 \%$ dos alunos referiram que gostariam de ter mais materiais/equipamentos laboratoriais e que cerca de $20 \%$ gostariam que nas escolas houvesse melhores instalações para a disciplina de TLQ. Estes resultados poderão dever-se às condições deficientes em que muitos alunos e professores têm que trabalhar e ser um reflexo da consciência que disso têm os próprios alunos.

Ao nível pedagógico-didáctico, os alunos participantes neste estudo alterariam diversos aspectos mas as alterações que seriam introduzidas por mais sujeitos iriam no sentido de passar a realizar experiências propostas pelos alunos $(19.6 \%)$ e de relacionar as experiências realizadas com o dia-a-dia $(16.7 \%)$. De notar ainda que um número considerável de alunos referiram que promoveriam o relacionamento das aulas teóricas com as aulas práti- 
cas, bem como o trabalho experimental realizado individualmente.

No que respeita às aulas práticas, e apesar de alguns alunos gostarem que cada aula tivesse uma duração menor, nenhum aluno afirmou que defenderia uma diminuição global das mesmas e, antes pelo contrário, $14.1 \%$ defenderiam mesmo o aumento da carga horária dedicada às aulas práticas, à custa da diminuição das aulas teóricas.

Apesar de alguns alunos terem afirmado que efectuariam alterações ao programa, eles não especificaram de que alterações se trataria. Também não foram explicitadas as razões pelas quais os alunos gostariam de introduzir aulas dedicadas a socorrismo. Contudo, pensamos que esta referência poderá estar relacionada com questões de segurança no laboratório, em consequência da ênfase que no programa é dada a este aspecto.

\section{CONCLUSÕES}

Para os alunos, a relação das aulas teóricas com as aulas experimentais é maior do que a relação das o dia-a-dia. Obviamente, é desejável que as aulas teóricas e as aulas expeexperiências realizadas em TLQ com

rimentais estejam relacionadas entre si mas seria bom que os alunos passassem a sentir mais que as actividades laboratoriais realizadas em TLQ têm relação com o seu dia-a-dia.

Conseguir isto pode não implicar uma alteração radical nas actividades realizadas, mas apenas que se crie condições para que a relação dessas actividades com o dia-a-dia se torne explícita para os alunos. $\mathrm{Na}$ verdade, se em alguns casos o próprio programa prevê e os autores de manuais propõem o ensino da técnica num contexto do dia-a-dia (ex: centrifugação no contexto da preparação do queijo), outros casos há em que isso não acontece. $\mathrm{O}$ que se defende é que, se a técnica tiver que ser ensinada num contexto académico, se faça, no momento que parecer mais oportuno mas de uma forma explícita, a ligação da mesma ao diaa-dia. Assim, por que não aplicar a floculação na interpretação do transbordar do leite, na preparação do chantilly e da clara em castelo (6)? Por que não dizer que a rotação do plano de polarização é usada para determinar a quantidade de açúcar em solução, nomeadamente, durante o fabrico do açúcar e do vinho (6) e na análise da urina (7) e, se possí-

QUADRO 1 - Alterações que os alunos implementariam em TLQ - Bloco I

\begin{tabular}{lcc}
\hline Alterações propostas & $\mathbf{f}$ & $\%$ \\
\hline Nível logístico: & 105 & 33.7 \\
- Mais materiais & 58 & 18.6 \\
- Mais/melhores instalações & & \\
\hline Nível pedagógico-didáctico: & 17 & 5.4 \\
- Fazer (mais) visitas de estudo/saídas de campo & 52 & 16.7 \\
- Relacionar as experiências com o dia-a-dia & 61 & 19.6 \\
- Realizar experiências propostas pelos alunos & 4 & 1.3 \\
- Permitir que os alunos elaborem protocolos & 3 & 1.0 \\
- Permitir que os alunos realizem projectos de investigação & 22 & 7.1 \\
- Trabalhar individualmente nas aulas práticas & 27 & 8.7 \\
- Relacionar as aulas teóricas com as aulas práticas & 21 & 6.7 \\
- Reduzir o número de relatórios & 9 & 2.9 \\
- Avaliar através de testes práticos & 28 & 9.0 \\
- Promover um bom relacionamento professor-aluno & & \\
\hline Nível organizacional/regulador & 11 & 3.5 \\
- Alterar o programa & 44 & 14.1 \\
- Aumentar as aulas práticas à custa das teóricas & 11 & 3.5 \\
- Diminuir a duração das aulas práticas, mantendo o número de horas & & \\
\hline Outras & 3 & 1.0 \\
- Aulas de socorrismo & 33 & 10.6 \\
- Não propõe alteraçôes & 10 & 3.2 \\
\hline - Não responde & & \\
\hline
\end{tabular}

Nota: A soma das percentagens ultrapassa os $100 \%$, dado que algumas respostas foram classificadas em mais do que uma categoria vel, complementar esta informação com uma visita de estudo ou com um videograma que demonstre a utilização e a importância da técnica nesse(s) contexto(s) do dia-a-dia?

Por outro lado, o que parece preocupar mais alunos são, sem dúvi$\mathrm{da}$, as condições materiais que, como sabemos, em diversas escolas, impedem a disciplina de TLQ de ser, tal como se refere no programa, uma disciplina predominantemente prática. Estas condições são ainda importantes na medida em que constituem uma espécie de condição necessária e/ou facilitadora da concretização de outros aspectos a que os alunos atribuem importância, como, por exemplo, mais aulas práticas, trabalho individual e realização de experiências propostas pelos alunos. Estas últimas constituíriam, ainda, uma oportunidade excelente para se promover a integração consciente de conhecimentos processuais e conceptuais (dificilmente conseguidas com a mera execução de protocolos que frequentemente apresentam estrutura tipo "receita de culinária"), desde que fosse dada aos alunos a oportunidade de, e tal como alguns deles referem, elaborarem os protocolos experimentais.

Nota: Parte deste trabalho foi apresentada em Poster no Encontro da SPQ-96.

Agradecimentos: As autoras agradecem a colaboração dos Professores e dos Alunos que tornaram possível este trabalho.

\section{* Instituto de Educação e Psicologia \\ Universidade do Minho \\ Campus de Gualtar - 4719 BRAGA CODEX}

\section{REFERÊNCIAS}

1. Gabinete de Educação Tecnológica, Artística e Profíssional, Técnicas Laboratoriais de Química - Programa., M.E., 1992.

2. B. Fraser, C. McRobbie, G. Giddings, Science Education. 77 (1993) 1-24.

3 D. Araúio, Técnicas Laboratoriais de Fisica: Análise e consequências do primeiro ano do seu funcionamento, Dissertação de mestrado (não publicada), Univ, do Minho, 1995.

4. R. De Vellis, Scale Development, theory and application Sage, 1991.

5. L. Cronbach, Essentials of psychological testing, Harper and Row. 1990.

6. I. Berkes, A Física do quotidiano, Gradiva, 1992.

7. E. Hecht, Óptica, Fundação Calouste Gulbenkian, 1991. 


\section{SÍNTESE, REACTIVIDADE E ESTRUTURA EM QUÍMICA INORGÂNICA}

$3^{a}$ Conferência de Química Inorgânica Sociedade Portuguesa de Química

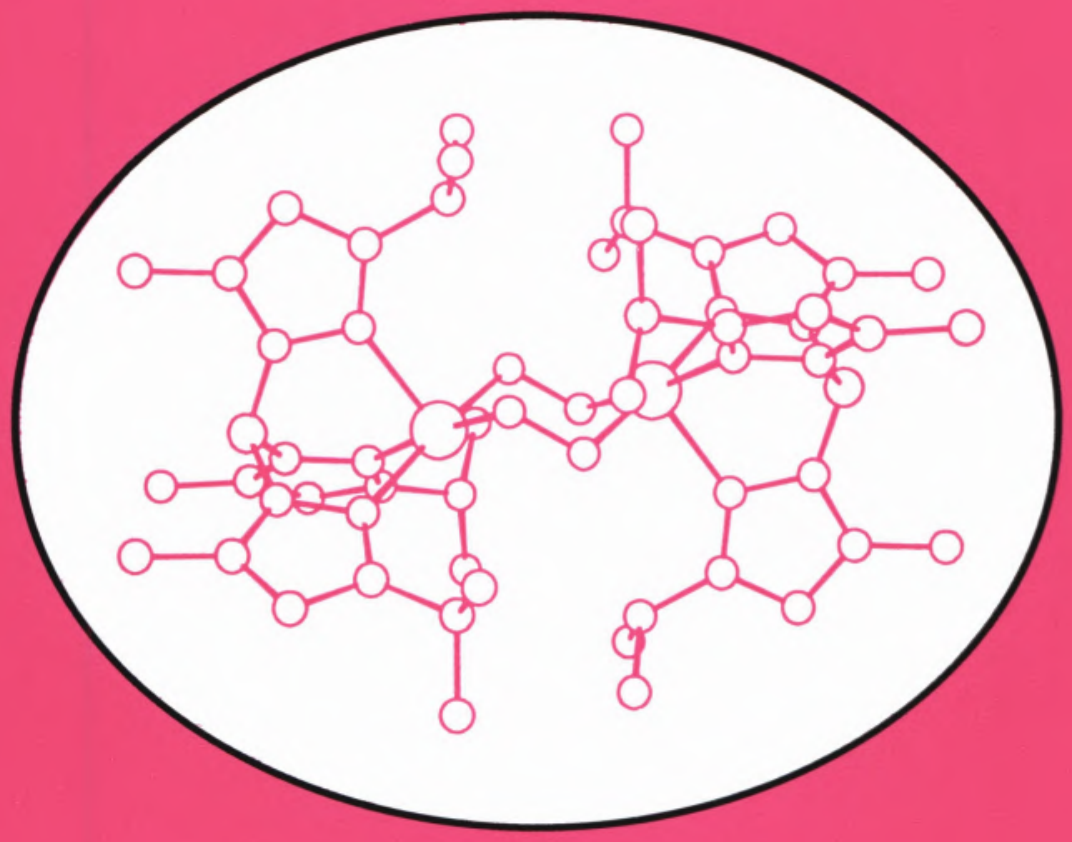

21 e 22 de Março de 1997

Fátima, Portugal

\section{Lições convidadas}

Klaus Theopold (Delaware, USA)

Cristina Freire (FC, Porto)

Luis Veiros (IST, Lisboa)

Noémia Marques (ITN, Lisboa)
Silvio Aime (Turim, Itália) João Pessoa (IST, Lisboa) Miguel Teixeira (FCT-UNL)

\section{Informações}


